\title{
A formação des(continuada) dos professores temporários: provisoriedade e qualidade de ensino
}

\section{The (dis)continued formation of the temporary teachers: eventuality and quality of teaching}

\section{Luiz Carlos Novaes}

Doutor em Educação pela Pontifícia Universidade Católica de São Paulo, professor adjunto de Políticas Públicas da Educação Brasileira na Universidade Federal de São Paulo (Unifesp), Guarulhos, SP - Brasil, e-mail: luiz.novaes@unifesp.br

\section{Resumo}

Este artigo discute a formação continuada de professores temporários em exercício na rede estadual paulista, considerada uma das maiores redes públicas de ensino do mundo. O trabalho realizado por tais docentes, principalmente os denominados eventuais, tem sido ignorado pelas administrações municipais e estaduais, que não valorizam a existência desses profissionais diante das elevadas taxas de absenteísmo docente, bem como sua importância para a garantia do cumprimento dos dias e horas letivas legalmente exigidos. Negligenciados pelas políticas educacionais no que tange aos investimentos na formação continuada e na valorização no âmbito da própria carreira, os professores temporários apresentam vínculos contratuais extremamente frágeis, o que interfere 
profundamente na constituição desse sujeito como professor, bem como na maneira de conceber a escola, a profissão e o ensino, fazendo-o relacionar sua condição transitória de professor temporário à natureza do trabalho que desenvolve, conferindo um caráter provisório e precário às próprias ações, o que fica expresso no emprego cada vez mais comum entre professores denominados eventuais, do termo "eventuar", ao invés de "lecionar", empobrecendo e simplificando o próprio trabalho, ao mesmo tempo em que colabora para a manutenção de um insuportável grau de improvisação e precariedade do trabalho pedagógico, repercutindo, profundamente, no seu processo de formação continuada.

Palavras-chave: Professores temporários. Formação continuada. Trabalho docente.

\section{Abstract}

The article discusses the continued formation of temporary teachers in exercise in the São Paulo state network, considered one of the biggest networks of public education in the world. The work done by these teachers, mainly the known by eventual, has been ignored by municipal and state administrations, that do not value the existence of those professionals given the high rates of teacher absenteeism, as well as her importance for the guarantee of the fulfillment of the days and academic hours lawfully required. Ignored by the educational politics with regard to the investments in the continued formation and the valorization in the scope of the own career, the temporary teachers has contractual links extremely fragile, what intervenes deeply with the constitution of this citizen as teacher, as well as in the way to conceive the school, the profession and the education, making relate his transitory condition of the temporary teacher to the own actions, marked by use of the term "eventuar" instead of "teach", causing the impoverishment and the simplification of the own work, at the same time in that collaborates for the maintenance of an unbearable degree of improvisation and precariousness of the pedagogical work, having deep repercussions in his trial of continued formation.

Keywords: Temporary teachers. Continued formation. Teaching work. 


\section{Introdução}

A maioria das redes públicas de ensino em todo o país admite em seu quadro de pessoal a presença de professores contratados em caráter temporário. O regime de contratação de professores é variado, e não menos variada tem sido a maneira como os professores são tratados, a depender de seu estatuto de contratação, em diferentes aspectos ligados à atuação profissional, inclusive em questões relacionadas à formação continuada. Nesse sentido, focalizaremos dois tipos de contratação de professores temporários bastante comuns na rede estadual de ensino de São Paulo, considerada uma das maiores redes públicas de ensino do mundo, bem como questões relacionadas à formação continuada, conforme tais estatutos de contratação. Trata-se dos professores admitidos em caráter temporário, denominados pela Secretaria de Estado da Educação de São Paulo (SEE/ $\mathrm{SP})$ como ocupantes de função atividade (OFAs) e, também, dos professores admitidos em caráter eventual, aqui denominado simplesmente por eventuais.

A contratação de professores temporários tem sido a alternativa encontrada por muitos sistemas de ensino para suprirem a carência de professores para áreas específicas, contudo, no caso paulista, a principal justificativa está relacionada às altas taxas de absenteísmo docente. Dados da própria SEE/SP apontam a existência de aproximadamente 37\% de professores temporários, na condição de OFAs, atuando na rede estadual de ensino, proporção que pode chegar a $44 \%$, se considerarmos, além dos OFAs, também os professores admitidos na condição de eventuais.

$\mathrm{Na}$ rede estadual paulista, a exemplo de outras redes de ensino no país, a principal estratégia para garantir dias e horas letivos foi a contratação de professores em caráter eventual, sem qualquer vínculo empregatício. Tais professores, licenciados ou em processo de formação, são contratados para suprir as ausências dos professores com aulas atribuídas (titulares ou OFAs), tendo seu salário calculado somente a partir das aulas efetivamente ministradas, criando, assim, uma subcategoria de professores dentro das unidades escolares. Para entender melhor tal processo, é preciso esclarecer como está organizado, no Estado de São Paulo, o quadro do magistério e o mecanismo pelo qual os docentes são contratados.

De acordo com o artigo $3^{\circ}$ da Lei Complementar n. 444/85, que dispõe sobre o estatuto do Magistério Paulista, o quadro do magistério pode ser definido como um "conjunto de cargos e de funções-atividades de 
docentes e de cargos de especialistas de educação, privativos da Secretaria de Estado da Educação". Em relação aos cargos, a legislação estabelece que seu provimento dar-se-á mediante concurso público e, em relação às funções, a mesma lei determina que o preenchimento das funções-atividades da série de classes de docentes será efetuado mediante admissão para reger classes e/ ou ministrar aula cujo número reduzido, especificidade ou transitoriedade não justifiquem o provimento de cargo; para reger classes e/ou ministrar aulas atribuídas a ocupantes de cargos ou de funções-atividades, afastados a qualquer título e, por fim, para reger classes e/ ou ministrar aulas decorrentes de cargos vagos ou que ainda não tenham sido criados. Temos assim, grosso modo, dois grandes grupos de professores: os efetivos e os não efetivos. Dessa forma, os chamados OFAs realizam o mesmo trabalho que os titulares e têm a mesma remuneração, mas não gozam da mesma estabilidade no emprego, vivendo, ano a ano, a insegurança e a instabilidade relacionada à possibilidade de se manterem empregados.

Esses professores, efetivos ou não, são classificados pela Lei Complementar n. 836/1997, que institui o plano de carreira, vencimentos e salários para os integrantes do quadro do magistério paulista, em duas classes: os Professores de Educação Básica I, comumente designados PEB I, que atuam nas quatro séries iniciais do ensino fundamental, e os Professores de Educação Básica II, designados PEB II, que atuam nas séries finais do ensino fundamental e no ensino médio. Existe uma diferença salarial entre as duas classes, contudo o PEB I pode ser remunerado como PEB II, conforme condições estabelecidas em lei, que não serão tratadas neste artigo. Temos, assim, duas classes de professores - PEB I e PEB II - que podem ser efetivos, quando nomeados por concurso público, ou admitidos para ocupar funçõesatividades, de caráter não efetivo. Consagram-se, assim, dentro de cada classe, duas subdivisões - PEB I titular ou PEB I OFA, PEB II titular ou PEB II OFA. Além dos professores titulares e OFAs, a rede estadual tem admitido de forma crescente outro tipo de professor: o professor eventual. Como o próprio nome indica, esse professor é admitido para exercer a docência eventualmente, na ausência de professores, ou por períodos curtos que não admitem a contratação de professores temporários (OFAs).

Essa rápida apresentação sobre a organização do magistério paulista é para que possamos compreender como se encontra estratificada a organização dos professores na rede estadual paulista e como tal estratificação interfere no processo de formação continuada desses docentes, tanto quanto 
na construção de um projeto pedagógico comprometido com a melhoria da qualidade de ensino. Além disso, não podemos deixar de destacar como a criação de mais uma situação de divisão interna à classe do magistério, no caso a dos professores eventuais, tem afetado, sobremaneira, não só o trabalho docente, mas, também, as concepções dos professores sobre o trabalho que realizam, a importância de tal trabalho e o lugar profissional que ocupam como no âmbito escolar.

\section{Do temporário ao eventual: a formação continuada e o estatuto de contratação}

Como anunciado no início deste artigo, o absenteísmo docente vem se apresentando como um grave problema na organização do trabalho pedagógico nas escolas públicas de todo país, o que fica agravado no caso do Estado de São Paulo, em virtude do número de escolas e de alunos matriculados na rede pública de ensino. A todo instante, alunos e pais acusam os professores de faltarem demasiadamente ao trabalho; a mídia, de diferentes formas, também veicula notícias destacando o absenteísmo docente, bem como o caráter permissivo da legislação paulista, que possibilita e até mesmo incentiva as faltas dos professores. Recentemente, assim divulgou o jornal Folba de S. Paulo:

Todos os dias, quase 30 mil dos 230 mil professores da rede estadual de ensino paulista faltam às aulas, e, amparados pela lei, a maioria não perde nenhum centavo dos seus vencimentos. O número significa uma ausência diária de 12,8\%. Dos 30 mil, menos de 2.400 têm faltas que acarretam perda de salário, segundo dados oficiais de 2006. Os docentes contam com 19 dispositivos legais que lhes permitem se ausentar sem desconto no salário, entre os quais licença médica, licença-prêmio (por assiduidade) e falta abonada por "motivo relevante" (seis ao ano neste caso). Em um desses mecanismos, o professor pode, no limite, faltar 100 dos 200 dias letivos, desde que apresente atestados médicos e que as ausências não sejam em dias seguidos. "Todos conhecem um médico que pode dar o atestado", disse o presidente da Udemo (representante dos diretores de escolas), Luiz Gonzaga Pinto, que defende melhores condições de trabalho aliadas a mudanças na lei. "Não estou dizendo que os professores abusam. Mas sempre há aqueles que buscam as brechas." [...] "A legislação na rede pública é muito permissiva", 
afirmou o promotor da Infância e Juventude da capital Motauri Ciocchetti de Souza, que investiga as causas das ausências. Já os professores dizem que as faltas são reflexo de más condições de trabalho. "Com jornadas extenuantes, classes superlotadas, o professor adoece, precisa ir ao médico ou se afastar", disse o presidente da Apeoesp (sindicato dos docentes), Carlos Ramiro de Castro. A rede possui 17.358 docentes eventuais, chamados para substituírem faltas. A secretaria diz que eles "são preparados", mas "é de se esperar" que tenham dificuldades com turmas novas. Por isso, estão sendo criadas referências de aulas (TAKAHASHI, 2007, p. C1).

Por outro lado, o Sindicato dos Professores do Ensino Oficial do Estado de São Paulo (Apeoesp) afirma que as condições de trabalho enfrentadas pelos docentes da rede estadual paulista é a principal geradora de estresse, provocando as chamadas "doenças profissionais". No mesmo artigo que denunciou o excessivo número de faltas docentes, assim argumenta o presidente do sindicato dos professores:

O presidente da Apeoesp (sindicato dos professores), Carlos Ramiro de Castro, afirmou que, com salários baixos, longas jornadas, salas superlotadas e violência na escola, os professores tendem a adoecer e, por isso, precisam faltar. Para sustentar a argumentação, Castro cita um estudo feito pela Apeoesp, em conjunto com o Dieese (Departamento Intersindical de Estatísticas e Estudos Socioeconômicos), que apontou que 61\% dos professores dizem sofrer de nervosismo, $57 \%$ têm falhas na voz e $44 \%$ apresentam angústia. A pesquisa, publicada neste ano, entrevistou 1.780 docentes em novembro de 2003. "Nessas condições, o professor adoece. E, como ele tem de fazer jornada tripla, se precisa ir ao médico, muitas vezes, tem de faltar", disse Castro. [...] Docentes também reclamam. "O professor não é valorizado, entra em depressão, tem problemas na voz. Eu estou desmotivado", diz um docente de uma unidade do Capão Redondo (zona sul de SP). Se não há consenso para as razões do absenteísmo, os efeitos são conhecidos. Vinícius Rodrigues Dantas, 17, por exemplo, se diz uma das vítimas. Aluno do terceiro ano do ensino médio de uma escola estadual na Cidade Ademar (zona sul), ele conta que "quase todo dia falta um professor". "Geralmente, os substitutos não fazem nada, deixam a gente conversando", disse ele, que decidiu não prestar vestibular neste final de ano. "Sei que não vou conseguir passar.” (TAKAHASHI, 2007, p. C1). 
A pesquisa a que se refere o presidente da Apeoesp no artigo anterior foi realizada pelo sindicato dos professores, mediante respostas a 1.780 questionários distribuídos entre os delegados presentes ao XIX Congresso Estadual de 2003. De acordo com o sindicato, os dados levantados apontaram que o alto índice de ausências dos docentes ao trabalho está relacionado às péssimas condições de trabalho, que afetam diretamente a saúde dos professores. Ainda segundo a pesquisa, as principais queixas dos professores estão profundamente relacionadas com o exercício da profissão, como cansaço, nervosismo, problemas com a voz, ansiedade, esquecimento e angústia, entre outros.

As questões apontadas pela pesquisa realizada pelo sindicato vêm sendo amplamente discutidas por vários pesquisadores, entre eles Esteve (1999), preocupado com as condições de trabalho dos professores e os impactos de tais condições sobre a saúde dos docentes e sobre o trabalho por eles realizado. Justificativas à parte, o fato é que ninguém discorda da existência de um grande número de faltas dos professores ao trabalho, situação que fica agravada quando não existem professores de algumas disciplinas escolares em quantidade suficiente para suprir a demanda do sistema de ensino, como é o caso, nesse momento, de Química e Filosofia, na rede estadual paulista. Segundo depoimento de aluno matriculado no ensino médio na rede estadual paulista:

Não tá adiantando mais a gente ir pra escola. Nunca tem todas as aulas. Nunca. No começo a gente saía mais cedo, agora, com os eventuais, a gente tem e não tem todas as aulas, sabe? Tem, porque é obrigado a ficar na sala, não tem porque eles não dão nada. Um ou outro dá alguma coisa, mas também não adianta nada, o pessoal não faz a atividade. No começo eu até fazia, mas depois vi que não adiantava pra nada. O professor que falton nem olha o que a gente fez com o eventual, e o eventual nem sabe o que o professor que faltou tá dando. Quase sempre eles nem são da mesma matéria. Veja, o professor de Biologia falta bastante, mas bastante mesmo. Filosofia a gente não tem professor. Ai entra um eventual na sala, geralmente professor de Português, Geografia on História, e vai dar redação, falar de notícias de jornal, coisas que aconteceram na semana, projeto de meio ambiente, de preservação, um monte de coisas... Menos aulas daquela matéria que o professor faltou. Quando chega ao final do ano a gente não aprendeu nada. Vestibular pra faculdade boa, nem pensar. Ai, ou faz. cursinho ou entra em qualquer dessas faculdades ruins (L.A.T, 16 anos, aluno do $2^{\circ}$ ano do ensino médio). 
Com ausências cada vez mais frequentes dos professores, além da carência de professores para disciplinas específicas, o número de aulas não ministradas na educação básica vem crescendo de forma assustadora, particularmente no ensino fundamental. Para tentar resolver o problema, ou ao menos parte dele, a Secretaria de Educação de São Paulo (SEE/SP), além dos professores admitidos mediante concurso público, bem como aqueles admitidos em caráter temporário, permite a existência de outra categoria de professor: o professor eventual. Esses professores, nem sempre habilitados, têm a difícil tarefa de cobrir as ausências dos professores, com poucas garantias e condições de trabalho.

Em recente pesquisa, Novaes (2005) detectou que um grande número de aulas deixa de serministrada diariamente em escolas públicas pelos professores titulares ou contratados no início do ano, sendo assumidas, na maioria das vezes, pelos professores denominados eventuais. O levantamento de aulas ministradas por professores eventuais, em diferentes componentes curriculares, em cinco turmas do período noturno de uma escola da rede estadual, revela que 32,9\% das aulas previstas foram ministradas por professores eventuais. Em alguns casos, a situação é ainda mais dramática, pois, com o elevado número de faltas dos professores responsáveis pelas disciplinas, e não existindo professores eventuais para cobrir tantas ausências, na mesma escola a quantidade de aulas não ministradas é de 7,3\%. Dessa forma, 40,2\% das aulas previstas não foram ministradas pelos professores responsáveis pelas disciplinas.

Os professores eventuais não têm vínculo empregatício e seus vencimentos referem-se, somente, às aulas efetivamente ministradas, além de receberem pela hora-aula ministrada um valor menor, quando comparada aos demais professores, ainda que possuam a mesma formação acadêmica. Tratase, na verdade, de um professor ignorado pelas políticas públicas, já que não existe no estatuto do magistério, tampouco é considerado no plano de carreira. A atuação desse profissional é igualmente precária, pois, como as ausências docentes não são geralmente comunicadas com antecedência (exceto nos casos de licenças médicas), os professores admitidos como eventuais só "descobrem" no momento da aula para qual turma irão e quais professores substituirão. $\mathrm{Na}$ Resolução SE 90/2005, que dispõe sobre o processo anual de atribuição de classes e aulas aos docentes do Quadro do Magistério de São Paulo, consta no parágrafo 18 do artigo 10:

Encerrada a atribuição da Etapa Complementar do processo inicial, a Comissão de Atribuição de classes e aulas divulgará e coordenará a atribuição de vagas para admissões em caráter 
eventual, aos inscritos no referido processo, que tenham interesse e condições de suprir as unidades escolares com carência de professores para iniciar o ano letivo, atribuição essa cuja admissão não caracterizará vínculo empregatício e se fará pelos Diretores de Escola, observando o campo de atuação relativo à vaga, a habilitação/qualificação dos inscritos, bem como a ordem de classificação na Diretoria de Ensino (RESOLUÇÃO SE 90, de $09 / 12 / 2005$ - grifo nosso)

Como fica evidente, além da Secretaria de Estado da Educação de São Paulo não desconhecer a carência de professores, embora a admita apenas para "iniciar o ano letivo", como afirma o texto da lei, também disciplina o processo de admissão de professores em caráter eventual, a ser feito pelos diretores de escola, observando, entre outras coisas, a "habilitação/ qualificação dos inscritos”. Dessa forma, pode atuar na condição de professor eventual nas escolas da rede pública estadual, a critério dos diretores de escola, todos os professores regularmente inscritos no processo anual de atribuição de aulas, sejam licenciados, alunos de curso de licenciaturas ou, ainda, bacharéis de cursos que constem, nos respectivos históricos escolares, carga horária mínima de 160 horas em alguma disciplina do currículo escolar, critério adotado pelas Diretorias de Ensino para inscrever os bacharéis de cursos diversos no processo anual de atribuição de aula.

Dessa forma, o professor admitido em caráter eventual está geralmente no início da carreira, ou às vezes nem ingressou nela ainda, como é o caso dos alunos das licenciaturas, e é aquele que, no processo anual de atribuição de aulas, não conseguiu ser admitido em caráter temporário, o chamado OFA. Caberá a esse professor eventual cobrir as ausências dos demais docentes, assumindo, quase invariavelmente, aulas de disciplinas e turmas para as quais não se encontra preparado, o que exigiria, por parte do sistema, uma atenção redobrada com a formação em serviço desses profissionais.

\section{Eventuar como sinônimo de lecionar: aprendendo a ser professor}

Embora a reflexão aqui proposta sobre os professores eventuais ainda parta de dados preliminares, é possível perceber que a presença desse profissional já vem despertando a reflexão de vários pesquisadores, como Patinha (1999) e Paiva (2002). As investigações realizadas por essas 
pesquisadoras demonstraram que a presença dos professores eventuais na rede estadual paulista cresce de ano a ano, sua existência tornandose quase que uma regra. Além disso, nos levantamentos que realizaram, demonstraram que tais professores atuam em diferentes disciplinas escolares, independentemente de sua formação, não constando nas estatísticas apresentadas pela Secretaria de Estado da Educação em virtude do artifício administrativo utilizado: classificá-los como PEB I.

A presença dos chamados professores eventuais na rede pública estadual paulista vem, a cada dia, sendo percebida por todos como uma questão que merece ser discutida. Submetidos às condições que pouco ou nada possibilitam a realização de um bom trabalho, os professores eventuais não recebem por parte do poder público nenhum incentivo que lhes permitam trabalhar com mais segurança, já que a maioria tem pouco tempo de experiência no magistério. Como já afirmamos, os professores eventuais não gozam dos mesmos direitos dos demais professores, não têm vínculo empregatício e são remunerados com um valor diferenciado em relação aos demais professores que tiveram aulas atribuídas, no entanto, nenhuma escola da rede estadual paulista pode abrir mão de sua existência. Segundo M.F.S.S., professora das séries iniciais na rede privada e diretora de escola estadual, os professores eventuais são "professores genéricos, podem ir para qualquer sala, substituir qualquer professor, dar aula de qualquer matéria, enfim, um quebra-galho que faz muita falta na escola, pois evita reposição de aula e ajuda a manter a disciplina." Essa sensação de "quebra-galho" também é compartilhada pelos próprios professores eventuais:

Quando terminei a faculdade, tentei pegar aulas. Nunca pensei que fosse tão difícil! Participei daquela atribuição de aulas que tem no início de ano, pra professores que não são efetivos. O que é aquilo? Parece uma feira, com um monte de gente brigando por emprego. Achei tudo aquilo deprimente. Como não consegui aulas, resolvi tentar como eventual. Procurei uma escola e perguntei ao diretor se eu podia eventuar lá. O diretor me pediu um projetinho e logo comecei a trabalhar. Acho que ele nem leu o tal projetinho, pois, no dia seguinte, me ligaram e me mandaram ir à escola. Como os professores faltam! Eu dou aulas todos os dias e nunca fiquei um dia sem aula. Pra falar a verdade, acho que ganho mais eventuando do que professor que foi admitido no início do ano. Agora, em relação ao trabalbo, não dá prá fazer quase nada. Os alunos não respeitam a gente, nos tratam como qualquer coisa, os professores, que deviam nos apoiar, são os primeiros que desconsideram o trabalho que a gente faz, nem olbam, nem corrigem, não valorizam. Os alunos já perceberam isso,

Rev. Diálogo Educ., Curitiba, v. 10, n. 30, p. 247-265, maio/ago. 2010 
então, tudo que a gente passa eles não fazem. Isso é muito complicado. A gente é, na verdade, estepe, tapa buraco. Quando eu chego à escola não tenho ideia onde vou dar aula. Tem que esperar os alunos entrarem e ver que sala está sem professor. Ai, a inspetora de alunos sai distribuindo as salas para os eventuais (M.C.F., professora, 29 anos, licenciada em Letras).

Para professores em início de carreira, essa experiência pode ser desastrosa. Logo de início vão construindo um jeito de ver e falar sobre a profissão. O caráter eventual do trabalho que realizam já foi incorporado à própria definição do trabalho. Tais professores eventuam, não lecionam. Comolecionar significa responder por determinada disciplina, ser responsável por uma sala, por uma turma, ser responsável pela atribuição de notas, e tais tarefas e responsabilidades, próprias da profissão, pertencem a outrem, cabendo-lhes, somente, suprir ausências de professores, atuando aqui e acolá, sem planejamento, de forma itinerante e provisória, os professores eventuais encontraram uma maneira que, pouco a pouco, foi se difundido entre eles, de se referirem à natureza do trabalho que realizam.

Enquanto muitos pesquisadores discutem o caráter ambíguo da docência, entre teses de profissionalização e proletarização, as condições de ser e estar na profissão dos professores eventuais é extremamente preocupante. O caráter precário do trabalho realizado pelos professores eventuais fica ainda mais evidente quando consideramos o fato de tais professores serem itinerantes. É preciso esclarecer que não se trata do professor itinerante, comum na educação especial, mas de uma situação de itinerância. Como não estão vinculados a nenhuma unidade escolar em particular, os professores eventuais podem ministrar aulas em mais de uma escola, cabendo àquela que os admitiram centralizar mensalmente as horas trabalhadas para efeito de pagamento. Dessa forma, ao perceberem que não existem tantas faltas docentes nas escolas que os admitiram, tais professores procuram por outras unidades escolares que possam precisar de seus serviços, o que os impede de participar da vida da escola, da reflexão acerca de seus problemas, enfim, da cultura escolar. Trata-se de uma situação perversa em que a manutenção do próprio trabalho depende da desagregação do trabalho pedagógico do próprio local de trabalho, em virtude do excessivo número de faltas dos docentes da unidade em que atuam. Essa situação de itinerância dos professores também é discutida por Dias-da-Silva (2006), embora não o faça especificamente em relação aos professores eventuais, mas, de forma geral, às condições de trabalho dos docentes paulistas: 
[...] À itinerância e ao absenteísmo agrega-se a rotatividade: a cada ano repete-se a possibilidade de troca de escolas. Seja advinda da solicitação de remoção pelo próprio professor (sempre interessado em lecionar em bairro mais próximo à sua residência, por necessidade econômica ou preocupado em aumentar seu status profissional, incorporando-se a um corpo docente de escola de maior prestígio, quase sempre localizado em bairros nobres da cidade), seja pela condição de precariedade de contrato de trabalho a que os professores mais jovens ou não efetivos são submetidos, repete-se anual, ou semestralmente, a possibilidade de troca(s) de escola(s), implicando desgaste físico e emocional para professores e membros do staff administrativo (DIAS-DA-SILVA, 2006, p. 6).

Nesse fragmento, a autora trata da situação de dois grupos de docentes: os denominados OFAs, que não são efetivos, mas têm vínculo empregatício com o sistema de ensino, e o segundo, embora não os mencionem, os eventuais, marcados pela "precariedade de contrato de trabalho". Em ambos os casos, existe a condição de itinerância, ou seja, mudar de escola ao longo do ano (se as aulas assumidas pelos OFAs for de substituição a outro docente, por exemplo) ou no próximo ano letivo, em novo processo de atribuição de aulas. No caso dos professores eventuais, essa itinerância é mais frequente, já que não existe vínculo empregatício com o sistema de ensino e, por isso, eles não têm os mesmos direitos que seus colegas professores OFAs ou titulares. Eles não são "professores", são "eventuais”, eles não exercem a docência, eles “eventuam”. Muitos se consideram, e são considerados, professores de segunda categoria, embora tenham a consciência de que a escola não funciona sem sua presença. Veja o depoimento deste professor de Matemática, admitido em caráter eventual.

Tentei várias vezes pegar aulas. Não consegui. No último concurso, não consegui passar. Então, apelei pra ser eventual. Não é difícil conseguir eventuar, os diretores é que admitem, não tem prova, burocracia, nada. Basta a gente ir à escola e perguntar se eles precisam de eventual e se a gente pode eventuar lá. Eventuar não é tão ruim. Dia você está aqui, outro dia lá. Ninguém fica te cobrando nada. Vão cobrar o quê? A gente está aqui pra não deixar o aluno sair mais cedo, pra não ter reposição de aula, pra família não reclamar quando o filho chega mais cedo em casa. Eu queria que fosse diferente, mas não é. É claro que en queria ter a minha sala, as minhas turmas, preparar as aulas, poder aplicar as provas, fechar as notas. Mas eventuaré isso, é quebrar o galbo, trabalhar com algumas coisinhas que 
não compromete a aula do professor que faltou. Teve um dia que faltou um professor de Matemática e eu fui para a sala dele. Também sou formado em Matemática. Vi onde ele tinha parado e dei matéria... Nossa! Foi um auê. A diretora me chamou e disse que eventual não podia dar matéria nova, quando muito, revisão. Me senti bumilhado, parecia até que eu não era também professor de Matemática. Então aprendi: dali pra frente iria fazer só o trivial, manter a ordem na sala e dar uns trabalbinhos - que poucos alunos fazem - e, depois, deixar com o professor que substituí, que também nem lê o que foi feito. Apesar de tudo isso, quero ver quem tem coragem de acabar com os eventuais. O dia que não tiver eventual, a escola fecha (P.F.N., 33 anos, professor, licenciado em Matemática).

O termo "eventuar" não é uma palavra qualquer, tampouco usada impunemente, até porque as palavras estão sempre carregadas de sentido e, nesse caso, pode exprimir muito mais do que um tipo de trabalho. Pode exprimir uma concepção sobre trabalho, especificamente sobre trabalho docente, sobre a escola, sobre os alunos e sobre o ensino. Muitos professores já licenciados, a cada ano, oscilam da condição de eventual à de responsável por um determinado número de aulas; tais situações se alteram, mas o professor continua sendo o mesmo sujeito. Ele não passa, a todo instante e de uma hora para outra, a encarar a escola, os alunos e o próprio trabalho porque teve, ou não, aulas atribuídas, porque continua sendo, ou não, eventual.

Nesse sentido, "eventuar" é mais do que uma situação transitória, é um aprendizado de como ser professor e de como constituir-se como tal. Como afirmam Tardif, Lessard e Lahaye (1991, p. 232), os saberes da experiência, adquiridos, por exemplo, por meio dos "macetes", dos modos de fazer, de organizar a sala de aula, entre outros, "surgem como núcleo vital do saber docente, a partir do qual os professores tentam transformar suas relações de exterioridade com os saberes em relações de interioridade com sua própria prática.” Considerando que a prática docente mobiliza diferentes saberes, os "saberes da experiência", adquiridos pelos professores eventuais e por eles validados, podem levar tais professores a construírem um modo de conceber e interpretar a própria profissão.

Construir a profissão docente, dar sentido e significado às ações que realizam, reconhecerem a importância do próprio trabalho, identificarem os fatores que interferem e condicionam as práticas, sem com isso sentiremse desqualificados, são desafios impostos aos professores que, na rede estadual paulista, trabalham na condição pouco confortável de eventuais. 
Não se pode desprezar ou ignorar a importância do universo institucional, nesse caso a escola, nesse processo de aprendizado da docência pelo qual passam os professores eventuais. As regras, prescrições, normas, nem sempre explicitadas, são interiorizadas por esses professores e utilizadas, muitas vezes, como uma gramática de exercício profissional e naquilo que o caracteriza, como, por exemplo, a própria formação.

\section{O horário de trabalho pedagógico e a formação (des) continuada diante da itinerância e da provisoriedade}

Os professores admitidos como temporários, sejam os OFAs ou os eventuais, reclamam de não receberem, por parte do poder público, a mesma atenção que é dirigida aos professores titulares de cargo,nomeados por concurso público. Ainda segundo tais professores, a maioria das ações destinadas à formação continuada dos professores em exercício, empreendidas pela SEE/ SP, são destinadas, inicialmente, aos professores efetivos, com a justificativa de que tais investimentos devem contemplar, em primeiro lugar, o atendimento daqueles docentes com vínculos mais permanentes com o sistema. A principal referência ao possível privilégio dos professores titulares, amplamente feita pelos professores entrevistados, teve como principal alvo o projeto bolsa mestrado, que concede bolsa de estudo ou redução de carga horária a professores que ingressem em cursos credenciados de pós-graduação - mestrado ou doutorado - no campo da educação ou na área curricular em que atuam. Tal projeto é limitado aos professores efetivos, não se estendendo a professores com outro estatuto de contratação.

Em que pesem tais reclamações, algumas questões exigem uma análise mais cuidadosa. Levantamento, ainda em andamento, demonstra a existência de um grande número de ações de formação empreendidas pela SEE/SP e destinada a todos os professores em exercício, sejam efetivos ou OFAs. Em relação a essas ações de formação, geralmente descentralizadas e sob responsabilidade das diretorias de ensino, às quais estão vinculadas as escolas, os professores reclamam da qualidade do processo de formação, apontando, segundo dados que recolhemos, a fragilidade das reflexões propiciadas por aqueles que atuam como formadores, geralmente colegas de profissão que se afastaram para esses órgãos para executarem tarefas de assessoria e, em alguns casos, se manterem na profissão com melhor 
remuneração. Nesse sentido, a maior queixa é a ausência de especialistas e pesquisadores em campos específicos do currículo, bem como a distância da universidade nesse processo de formação em serviço. Segundo os professores entrevistados, a formação propiciada pela SEE/SP trabalha com recursos materiais e humanos da própria secretaria, com vistas a implementar, a todo custo, diretrizes da política educacional.

Além da qualidade dos formadores, apontada pelos professores, tanto temporários como efetivos, também chama a atenção a persistência com que a ausência de formação continuada em horário de serviço é apontada. Os professores reclamam que, em virtude da carga horária e jornadas de trabalho extenuantes, não dispõem de tempo para frequentarem cursos de formação oferecidos pela Secretaria de Educação, o que poderia ser evitado se tais cursos ocorressem no horário de trabalho, com a dispensa do horário de serviço, aos interessados em frequentá-los, com regras definidas institucionalmente, como, por exemplo, um docente por escola que, posteriormente, agiria como professor multiplicador.

A distância da universidade do processo de formação continuada, a qualidade dos recursos materiais e humanos, o privilégio de professores titulares ou a carga horária de trabalho, motivos apontados pelos professores paulistas como dificultadores no processo de formação continuada, traz à tona um dado muito importante: a maioria dos professores entrevistados não considera as três horas semanais, incorporadas à carga horária de trabalho, para atividades pedagógicas coletivas, denominada Horário de Trabalho Pedagógico Coletivo (HTPC), como um momento de formação continuada, embora tal horário seja remunerado, incorporado à jornada de trabalho, sem atendimento aos alunos e realizado coletivamente, sob a coordenação de um professor coordenador pedagógico (PCP). Embora ocorra dentro do horário de trabalho do professor, a maioria dos professores apontou que esse momento é utilizado para informes de natureza administrativa ou, ainda, destinado à leitura de documentos da própria Secretaria de Educação, sendo pouco utilizado para a discussão e reflexão acerca do trabalho pedagógico e, quando isso acontece, fica restrito às discussões sobre questões pontuais, como as relacionadas à indisciplina escolar, por exemplo.

O quadro descrito fica agravado se considerarmos que o limite de três horas semanais está restrito aos professores com, no mínimo, 28 aulas semanais; para aqueles com carga horária inferior, a maioria de professores temporários (OFAs), esse número pode ser reduzido a uma ou duas horas 
semanais, além disso, o número de escolas em que o professor atua pode "pulverizar" esse horário, caso ele venha dividir as parcas três horas em mais de uma escola em que trabalha. Se a situação dos OFAs é bastante complexa em relação ao processo de formação em serviço, no âmbito do chamado HTPC, dramática é a situação dos professores eventuais. Em virtude da fragilidade do estatuto de contratação, tais professores não têm direito ao horário de trabalho pedagógico e não são remunerados para nada além das aulas ministradas. Admitidos para substituírem professores ausentes ao serviço, e nem sempre para a disciplina para a qual são formados (ou estão se formando), esses professores são ignorados em todos os programas e projetos de formação continuada promovidos pela administração estadual. Simplesmente não existem, embora sejam os grandes responsáveis-juntamente com os OFAs - pela manutenção do funcionamento das escolas estaduais.

\section{Considerações finais}

Discutir o processo de formação continuada de professores temporários deveria ser, para um grande número de redes públicas de ensino de todo o país, uma prioridade a ser perseguida pelas administrações estaduais e municipais, responsáveis pelo atendimento e oferta da educação básica. No caso paulista, muitos professores admitidos como temporários acabam se aposentando nessa condição, o que demonstra que tal situação nada tem de temporária, pelo contrário, há mais de três décadas, em São Paulo, a Lei n. 500/74 já disciplinava a contratação desse profissional.

Os professores temporários são cada vez mais frequentes na rede estadual paulista. Trata-se, na verdade, de uma consequência direta do absenteísmo docente, aliado ao desemprego, que afeta um grande número de categorias profissionais em todo o país. Quando começaram a ser contratados, os eventuais eram, em sua maioria, alunos de cursos de licenciatura que, por não terem concluído seus cursos, não podiam prestar concursos ou assumirem aulas como professores admitidos em caráter temporário. A admissão como professor eventual foi, para muitos, a porta de entrada no magistério.

Embora a presença de tais professores seja obrigatória para o funcionamento das unidades escolares, pouco tem sido feito em relação a eles. Convivem com a ambiguidade de serem úteis, sem serem importantes. Não estão contemplados no plano de carreira, não existem no estatuto do

Rev. Diálogo Educ., Curitiba, v. 10, n. 30, p. 247-265, maio/ago. 2010 
magistério e não são remunerados para participarem, como os demais colegas professores, do horário de trabalho pedagógico coletivo, que em São Paulo convencionou-se a ser chamado de HTPC. As aulas que ministram valem menos, ainda que licenciados. No âmbito escolar, o trabalho realizado pelos professores eventuais não é valorizado pelos alunos, pelos demais professores e, tampouco, pela direção da escola. Mais do que a negação do trabalho que realizam, é o não reconhecimento desses professores como, de fato, professores.

Se o exercício da docência é, em si, um momento de aprendizagem, esses professores temporários estão recebendo uma péssima lição. Uma lição amarga de desvalorização profissional, de fragilidade do trabalho coletivo, de ausência de uma gestão verdadeiramente democrática, de um descaso da política educacional, mas, sobretudo, da importância da instituição escolar e do trabalho que nela se desenvolve. Diante disso, causa perplexidade a falta de investimento no processo de formação continuada dos professores admitidos na condição de temporários, principalmente os denominados eventuais. Suas precárias condições de trabalho, sua falta de vínculo com as escolas em que atuam, a diferença de remuneração a que são submetidos, a pluralidade de disciplinas escolares que diariamente têm de assumir, entre outras, são situações que exigem um investimento maciço das administrações públicas no processo de formação continuada, em serviço, desses profissionais; afinal, não há projeto pedagógico que possa resistir a graus tão altos de improvisação e, porque não, de deformação.

\section{Referências}

DIAS-DA-SILVA, M. H. G. F. As condições de trabalho dos professores e o trabalho coletivo: mais uma armadilha das reformas educacionais neoliberais? In: SEMINÁRIO DA REDESTRADO - REGULAÇÃO EDUCACIONAL E TRABALHO DOCENTE, 6., 2006, Rio de Janeiro. Anais... Rio de Janeiro: UERJ, 2006. p. 6.

ESTEVE, J. M. O mal-estar docente: a sala de aula e a saúde dos professores. Bauru: EDUSC, 1999.

NOVAES, L. C. A escola perdida: a boa escola e o bom aluno no discurso de pais e professores. 2005. 243 f. Tese (Doutorado em Educação) - Pontifícia Universidade Católica de São Paulo, São Paulo, 2005. 
PAIVA, M. M. Professor não habilitado: agora um sujeito ocultado no magistério público paulista. 2002. 235 f. Dissertação (Mestrado em Educação) - Pontifícia Universidade Católica de São Paulo, São Paulo, 2002.

PATINHA, V. A. Professor não habilitado: um sinal da crise na educação. 1999. 212 f. Tese (Doutorado em Educação) - Pontifícia Universidade Católica de São Paulo, São Paulo, 1999.

SÃO PAULO. Assembleia Legislativa do Estado de São Paulo. Lei n. 500/74, de 13 de novembro de 1974. Institui o regime jurídico dos servidores admitidos em caráter temporário e dá providências correlatas. Diário Oficial do Estado São Paulo, São Paulo. Disponível em: <http://www.al.sp.gov.br/repositorio/ legislacao/lei/1974/lei\%20n.500,\%20de\%2013.11.1974.htm>. Acesso em: 02 fev. 2009.

- Assembleia Legislativa do Estado de São Paulo. Lei Complementar n. 444, de 27 de dezembro de 1985. Dispõe sobre o Estatuto do Magistério Paulista e dá providências correlatas. Diário Oficial do Estado São Paulo, São Paulo. Disponível em: <http://www.al.sp.gov.br/repositorio/legislacao/lei\%20 complementar/1986/lei\%20complementar\%20n.499,\%20de\%2029.12.1986. htm>. Acesso em: 15 jan. 2009.

. Lei Complementar n. 836, de 31 de dezembro de 1997. Institui Plano de Carreira, vencimentos e salários para os integrantes do Quadro do Magistério da Secretaria da Educação e dá providências correlatas. Diário Oficial do Estado São Paulo, São Paulo, v. 107, n. 251. Disponível em: < http:/ / lise.edunet.sp.gov. br/paglei/notas/leicomp836_97.htm>. Acesso em: 28 jan. 2009

Resolução SE n. 90, de 9 de dezembro de 2005. Dispõe sobre o processo anual de atribuição de classes e aulas aos docentes do Quadro do Magistério de São Paulo. Diário Oficial do Estado São Paulo, São Paulo. Disponível em: <http://siau.edunet.sp.gov.br/ItemLise/arquivos/notas/90-05. HTM?Time=2/15/2010\%207:33:38\%20PM>. Acesso em: 10 fev. 2009.

SINDICATO DOS PROFESSORES DO ENSINO OFICIAL DO ESTADO DE SÃO PAULO - APEOESP. A saúde dos professores. São Paulo: APEOESP, 2003. Disponível em: <http://apeoespsub.org.br/especiais/saude_professor. htm>. Acesso em: 25 jan. 2009. 
TAKAHASHI, F. 30 mil professores faltam por dia na rede pública de SP. Folha de S. Paulo, Caderno Cotidiano, C1, 11 nov. 2007. Disponível em: <http://www1. folha.uol.com.br/fsp/cotidian/ff1111200712.htm>. Acesso em: 18 abr. 2009.

TARDIF, M.; LESSARD, C.; LAHAYE, L. Os professores face ao saber: esboço de uma problemática do saber docente. Teoria \& Educação, n. 4, p. 215-233, 1991.

Recebido: 09/05/2009 Received: 05/09/2009

Aprovado: 21/06/2009 Approved: 06/21/2009 